\section{Jean Rommelaere}

\section{ADRESSE}

J. Rommelaere : directeur de recherche $\dot{a}$ l'Inserm et professeur à l'Université libre de Bruxelles. Unité d'oncologie moléculaire, Inserm U186/Cnrs URA1160, Institut Pasteur de Lille, 1, rue Calmette, BP 245, 59019 Lille Cedex, France. Département de biologie moléculaire, Université libre de Bruxelles, 67, rue des Chevaux, 1640

\title{
Action anticancéreuse des parvovirus
}

Le cycle lytique des parvovirus semble dépendre de facteurs cellulaires qui sont modifiés au cours de la prolifération cellulaire et dans les cellules cancéreuses. De ce fait, ces virus sont doués de propriétés oncosuppressives vis-à-vis de différents types de cellules transformées, y compris des cellules humaines. Des études complémentaires sont nécessaires pour déterminer si des infections in vivo par des parvovirus ont une place dans la prévention et le traitement des cancers chez l'homme.

'intérêt fondamental et clinique suscité par les parvovirus repose sur la subordination de leur cycle lytique à des fonctions cellulaires dont l'expression dépend de la prolifération et de la différenciation. La transformation néoplasique de diverses cellules de mammifères, en particulier humaines, s'accompagne fréquemment d'une modification de leur sensibilité à l'attaque parvovirale. L'oncotropisme de ces virus et leur aptitude à lyser ou normaliser des cellules transformées, ont été démontrés respectivement in vivo et in vitro. Chez des animaux de laboratoire, certains parvovirus exercent une activité d'oncosuppression qui peut avoir pour cibles des greffes de cellules tumorigènes humaines. Ces propriétés débouchent sur l'espoir d'utiliser les parvovirus comme sondes pour caractériser le processus de transformation maligne. Il reste à détermi- ner si la protection anticancéreuse conférée à l'animal par ces virus peut être exploitée au niveau thérapeutique chez l'homme.

La famille des Parvoviridae regroupe une trentaine de virus apparentés par leur structure et l'organisation de leur génome. Ces petits virus sphéroïdaux ont la taille d'une sous-unité ribosomale (diamètre avoisinant $20 \mathrm{~nm}$ ) et sont dépourvus d'enveloppe ; leur génome consiste en une molécule linéaire d'ADN monocaténaire et est de l'ordre d'un million de fois plus petit que le génome humain (environ 5000 nucléotides) [1, 2]. A titre d'exemple, la carte génétique de l'un des parvovirus les mieux caractérisés, le virus Minute de la souris (MVM : minute virus of mice) est représenté sur la figure 1. Le chromosome parvoviral renferme un nombre restreint de gènes. Les moitiés gauche et droite du génome codent respectivement 


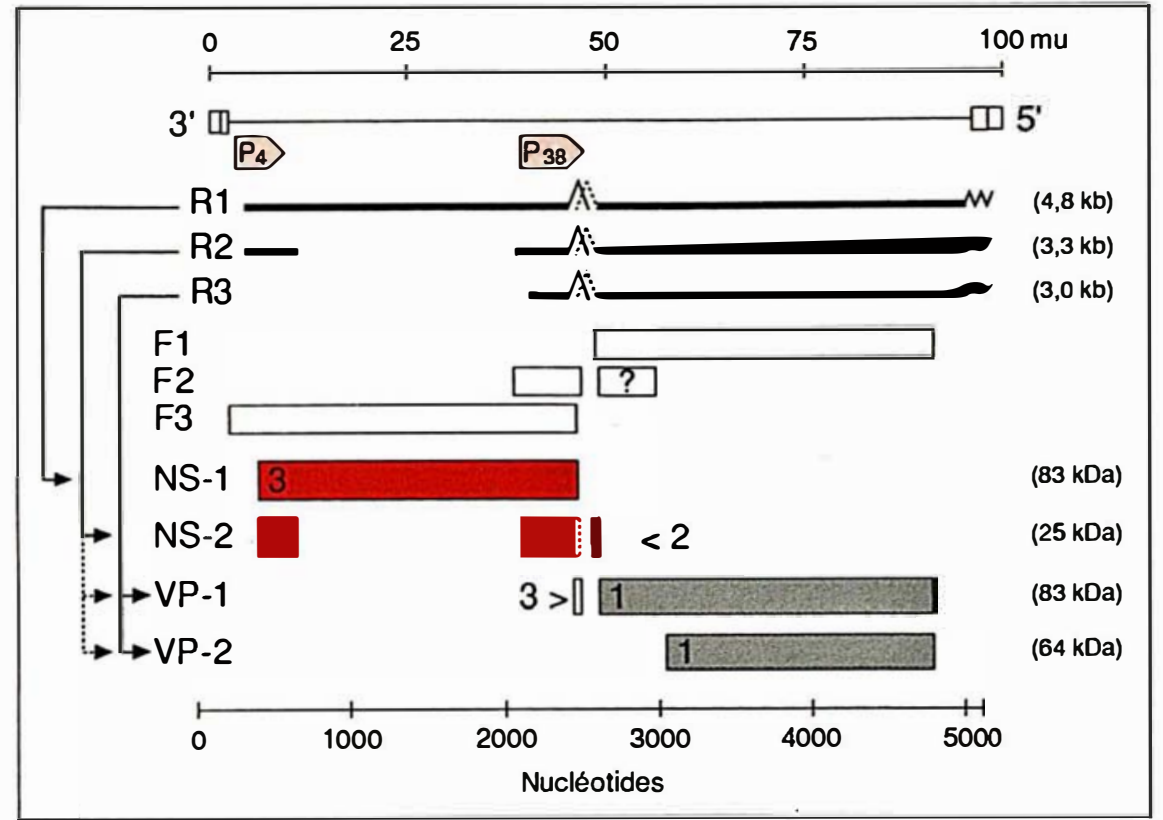

Figure 1. Représentation schématique de l'organisation génétique du génome du parvovirus MVM (d'après [1]). $\square$; séquences palindromiques terminales; $m u$ : unités cartographiques; $P$ : probmoteur ; $R$ : transcrit ; $F$ : cadre de lecture; NS : protéine non structurale; VP: protéine de capside; $k b$ : kilobases; $k D a$ : kilodaltons. Les chiffres 1, 2, 3 figurant dans les cadres font référence aux phases de lecture utilisées.

pour des protéines de régulation contrôlant la réplication et l'expression de l'ADN viral, et des protéines de structure qui entrent dans la constitution de la capside [3]. Les parvovirus parasitent certains insectes, des oiseaux et de nombreuses espèces de mammifères, y compris l'homme [4]. La faible complexité génétique des parvovirus exacerbe la subordination de leur réplication à des fonctions cellulaires. L'intérêt fondamental suscité par ces virus réside dans le fait qu'ils utilisent des facteurs assistants dont la disponibilité dépend des états de prolifération et de différenciation cellulaires [1]. Les parvovirus peuvent ainsi servir de sondes pour l'analyse du contrôle de ces processus. Dans certains cas, l'incapacité d'une cellule à répliquer un parvovirus peut être levée en présence d'adéno- ou d'herpèsvirus. Cette aide virale est flagrante pour le sousgroupe des parvovirus adéno-associés (AAV) qui ne peuvent se répliquer de façon autonome que dans des situations très particulières [2].

$\mathrm{m} / \mathrm{s} n^{\circ} 6$ vol. 6 , juin 90

Le présent article est consacré en majeure partie à ces derniers virus. La sélectivité de certains parvovirus se manifeste également par leur oncotropisme. Il est en eff et remarquable qu'une fraction importante des souches parvovirales ait été isolée à partir de matériel tumoral, en l'absence de contamination décelable des tissus sains correspondants. L'association fréquente des parvovirus et des néoplasmes a conduit initialement à envisager la possibilité d'une activité oncogène de ces agents, notamment chez l'homme. Cette éventualité n'a toutefois pas été étayée par des expériences ultérieures. L'infection parvovirale n'est en aucun cas associée à un risque accru de cancer. Il semble donc que la relation entre tumeurs et parvovirus soit de nature opportuniste, les premières fournissant un milieu particulièrement favorable à la multiplication des seconds [5]. Ce faisceau d'observations suggère que, dans certaines conditions, des parvovirus pourraient interférer avec le développement tumoral. Une telle " oncosuppression" a effectivement été démontrée et fait l'objet de la discussion qui suit.

\section{Tropisme parvoviral}

Le déroulement, parfois même incomplet, du cycle de vie parvoviral entraîne généralement la lyse cellulaire [1]. Toutefois, le besoin d'une assistance cellulaire ou virale très spécifique pour la réplication des parvovirus, restreint la population de cellules pouvant servir de cibles à ces virus. De nombreuses cellules sont réfractaires à l'infection parvovirale, soit par manque de récepteurs de surface pour l'adsorption des particules parentales, soit - cas le plus fréquent - par inadéquation du milieu intracellulaire à la poursuite du cycle viral. Ces limitations confèrent une grande spécificité à la pathogenèse parvovirale. Ainsi l'homme peut-il être infecté par un parvovirus, B19, qui s'attaque préférentiellement à la lignée érythroĩde et provoque des crises aplasiques dans certaines circonstances [4]. D'autres parvovirus dont l'être humain est l'hôte fréquent (AAV) ou occasionnel (H-1) ne sont associés à aucune affection reconnue.

\section{Inhibition de la cancérogenèse par les parvovirus}

La découverte de l'action anticancéreuse des parvovirus remonte aux travaux précurseurs de Helen Toolan qui a rapporté, dès 1967, que des hamsters infectés de façon chronique par des virus $\mathrm{H}$ développaient de 5 à 25 fois moins de tumeurs spontanées que des animaux contrôles. Des études ultérieures ont montré que cette surveillance parvovirale peut également s'exercer à l'encontre de divers types de tumeurs induites expérimentalement chez des rongeurs par des virus oncogènes ou un agent cancérigène chimique (Tableau $1 A$, page suivante). Cette oncosuppression pourrait résulter d'une interférence parvovirale avec l'induction de la transformation maligne et/ou avec la survie ou la croissance des cellules tumorales. Il apparaîtra ci-dessous que les parvovirus exercent in vitro des activités compatibles avec ces deux types d'effets. La seconde possibilité - la suppression de cellules 


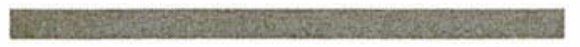

\section{RÉFÉRENCES}

1. Cotmore SF, Tattersall P. The autonomously replicating parvoviruses of vertebrates. Adv Virus Res 1987 ; 33 : 91-169.

2. Berns KI, Bohenzky RA. Adenoassociated viruses : an update. Adv Virus Res $1987 ; 32: 243-307$

3. Berns KI, Labow MA. Parvovirus gene regulation. J Gen Virol 1987 ; 68 : 601-14.

4. Perol Y. Les infections à parvovirus. $L a$ Presse Médicale 1988 ; 17 : 1834-5.

5. Rommelaere J, Tattersall P. Oncosuppression by parvoviruses. In : Tijssen $\mathrm{P}$, ed. Handbook of Parvoviruses. Boca Raton : CRC Press, 1990, vol. II : 41-57.

6. Kirchstein RL, Smith KO, Peters EA. Inhibition of adenovirus 12 oncogenicity by adeno-associated virus. Proc Soc Exp Biol Med $1968 ; 128: 670-3$.

7. Toolan HW, Ledinko N. Inhibition by $\mathrm{H}-1$ virus of the incidence of tumors produced by adenovirus 12 in hamsters. Viro$\log y 1968 ; 35$ : 475-8

8. Mayor HD, Houlditch GS, Mumford DM. Influence of adeno-associated satellite virus on adenovirus-induced tumors in hamsters. Nature New Biol 1973 ; 241 : 44-6.

9. De la Maza L, Carter BJ. Inhibition of adenovirus oncogenicity in hamsters by adeno-associated virus DNA. J Natl Cancer Inst 1981; 67 : 1323-6.

10. Siegl G. Biology and pathogenicity of autonomous parvoviruses. In : Berns KI ed. The Parvoviruses. New York: Plenum Press, 1984 : 297-362.

11. Bergs VV. Rat virus-mediated suppression of leukemia induction by Moloney virus in rats. Cancer Res. 1969; 29 . 1669-73.

12. Toolan HW, Rhode SL, Gierthy JF. Inhibition of 7, 12-dimethylbenz(a)anthracene-induced tumors in Syrian hamsters by prior infection with $\mathrm{H}-1$ parvovirus. Cancer Res $1982 ; 42$ : 2552-5.

13. Ostrove JM, Duckworth DH, Berns KI. Inhibition of adenovirus-transformed cell oncogenicity by adeno-associated virus.

\begin{tabular}{|c|c|c|c|}
\hline \multicolumn{4}{|c|}{$\begin{array}{l}\text { Tableau I } \\
\text { ITEUR DES PARVOVIRUS } \\
\text { UCTION DE TUMEURS a }\end{array}$} \\
\hline Traitement cancérogène ${ }^{b}$ & Hôte & $\begin{array}{l}\text { Agent parvoviral } \\
\text { anticancéreux }{ }^{c}\end{array}$ & Référence \\
\hline $\begin{array}{l}\text { A. Adénovirus (Ad 12, Ad 31) } \\
\text { Papovavirus (SV40) } \\
\text { Herpèsvirus (MDV) } \\
\text { Rétrovirus (MoMuLV) } \\
\text { Carcinogène chimique } \\
\text { (DMBA) }\end{array}$ & $\begin{array}{l}\text { Hamster } \\
\text { Hamster } \\
\text { Poulet } \\
\text { Rat } \\
\text { Hamster }\end{array}$ & $\begin{array}{l}H-1, \text { AAV }-1, \text { AAV }-2 \\
H-1 \\
\text { AAAV } \\
\text { RV } \\
H-1\end{array}$ & $\begin{array}{c}6-9 \\
10 \\
d \\
11 \\
12\end{array}$ \\
\hline $\begin{array}{l}\text { B. Cellules tumorigènes greffées } \\
\text { - cellules de rongueur } \\
\text { transformées } \\
\text { - par un adéno- } \\
\text { ou herpèsvirus } \\
\text { (Ad 5, Ad 12, HSV-2) } \\
\text { - par un oncogène } \\
\text { cellulaire (c-Ha-ras 1) } \\
\text { - cellules humaines } \\
\text { transformées par } \\
\text { un papovavirus (SV40) } \\
\text { - cellules tumorales animales }\end{array}$ & $\begin{array}{l}\text { Hamster } \\
\text { Souris } \\
\text { Souris } \\
\text { Chien, } \\
\text { souris }\end{array}$ & $\begin{array}{l}\text { AAV-1, AAV-2 } \\
\text { AAV-2 } \\
H-1 \\
\text { FPV, CPV, MVMp }\end{array}$ & $\begin{array}{c}9,13-15 \\
16 \\
17 \\
18,19\end{array}$ \\
\hline
\end{tabular}

a Inhibition de la cancérogenèse $\geqslant 50 \%$.

b Ad: Adénovirus; SV : Simian Virus; MDV: Marek's Disease Virus; MoMuLV: Moloney Murine Leukemia Virus ; DMBA : 7,12-Dimethylbenz(a)anthracene ; HSV : Herpes Simplex Virus.

c Inoculation de parvovirus : (A) à des animaux nouveau-nés, au moment du traitement cancérogène ou avant celui-ci; (B) aux cellules néoplasiques avant la transplantation ou aux animaux ayant subi la transplantation. H: Hamster-Osteolytic Virus; AAV : Adeno-Associated Virus ; AAAV: Avian Adeno-Associated Virus ; RV : Rat Virus ; FPV : Feline Parvovirus : CPV : Canine Parvovirus : MVMp : Minute Virus of Mice (prototype). ¿ Paul et Monreal (1989), Proc. EMBO Workshop "Molec. Biol. of Parvoviruses ", p. 45.

transformées préétablies - a été démontrée in vivo par une série d'expériences indiquant que les parvovirus sont capables d'empêcher le développement tumoral de greffes de cellules transformées dans des animaux receveurs (Tableau I B). Le degré de protection conféré par les parvovirus dépend du programme d'inoculation et des quantités relatives de virus et de cellules néoplasiques en présence. Il convient de souligner que des cellules transformées humaines peuvent servir de cibles à la surveillance parvovirale. Un travail récent réalisé dans notre laboratoire montre en effet que le parvovirus $\mathrm{H}-1$ exerce une action antitumorale préventive et, dans une moindre mesure, curative, contre des implants de cellules épithéliales mammaires humaines dans des souris nude, et ceci en l'absence d'effets secondaires décelables (figure 2).
A ce jour, le phénomène d'oncosuppression parvovirale est une "boîte noire " dont l'analyse est encore à ses ble que les parvovirus n'entrent pas en contact avec les cellules (pré)néoplasiques elles-mêmes et perturbent celles-ci indirectement, par l'intermédiaire d'effecteurs physiologiques (système immunitaire, interférons...) dont ils moduleraient la production ou l'activité. Par ailleurs, certains arguments expérimentaux plaident en faveur de l'intervention d'une interaction directe entre les parvovirus et au moins une fraction des cellules transformées. Ainsi, des empreintes parvovirales ont été décelées dans des tumeurs en régression [17]. De plus, dans l'un des systèmes étudiés, l'obtention d'un effet d'oncosuppression s'est avérée dépendante de l'utilisation d'une souche parvovirale infectieuse, capable de se répliquer débuts. A l'extrême, il est conceva- 
dans les cellules tumorales utilisées [19]. Il paraît donc vraisemblable que l'aptitude des parvovirus à interagir directement avec les cellules néoplasiques contribue à la suppression de ces dernières, même si l'importance de cette composante dans le taux global d'inhibition de la cancérogenèse est encore difficile à apprécier.

\section{Interférence parvovirale avec la vie cellulaire}

A défaut d'informations sur les autres effets physiologiques possibles des parvovirus, cette discussion sera focalisée sur la nature des troubles que ces virus sont susceptibles d'occasionner dans les cellules transformées. Le Tableau II (page suivante) dresse la liste des facteurs parvoviraux dont l'interférence avec la vie cellulaire est soupçonnée ou démontrée. Des effets directs sur le métabolisme cellulaire sont imputés aux séquences terminales de l'ADN viral ainsi qu'aux protéines non structurales (appelées NS ou Rep selon l'agent considéré). L'analyse de particules "déf ectives" suggère que les extrémités non codantes du génome parvoviral, qui renferment des signaux d'initiation de la réplication et de la transcription [1, 3] (figure 1), participent à l'inhibition d'une réponse fréquemment associée à la transformation maligne, à savoir l'amplification de l'ADN. Il est possible que les terminaisons génomiques parvovirales interagissent avec des facteurs cellulaires d'amplification de l'ADN et empêchent ainsi l'induction de ce processus par les agents cancérigènes d'initiation. D'autre part, les protéines non structurales exercent une action pléiotrope dont certaines facettes sont susceptibles de contribuer à l'inhibition de la transformation et/ou à la destruction des cellules néoplasiques. Les protéines NS/Rep sont en effet capables de perturber l'amplification de l'ADN et l'expression génique contrôlée par des promoteurs hétérologues ; elles semblent également douées d'un pouvoir cytocide. Enfin, les parvovirus peuvent avoir une action cytostatique dont les effecteurs sont des constituants encore indéterminés des virions.

$\mathrm{m} / \mathrm{s} n^{\circ} 6$ vol. 6 , juin 90
Outre ces effets directs, des influences plus détournées des parvovirus sur le devenir des cellules tumorales méritent d'être envisagées. Certains virus enveloppés produits par bourgeonnement au niveau de la membrane plasmique, accroissent le caractère immunogène des cellules tumorales qu'ils infectent et favorisent ainsi leur rejet [5]. Les parvovirus sont $a$ priori peu efficaces de ce point de vue car ils sont assemblés dans le noyau et sont généralement libérés lors de la lyse de la cellule hôte [1]. L'affichage de déterminants antigéniques parvoviraux à la surface des cellules infectées ne peut toutefois pas être exclu et rendrait compte de cer- taines observations suggérant l'existence d'une composante immunitaire de la réponse oncosuppressive. Cette éventualité est étayée par le fait que l'infection parvovirale stimule des indicateurs immunologiques potentiels, comme l'enraiement des métastases et la vaccination contre des implantations de cellules tumorales réalisées par un prétraitement combiné de l'animal à l'aide de ces cellules et de parvovirus. Il est donc possible que certains aspects, en particulier tardifs, de l'oncosuppression parvovirale impliquent une réaction immunologique provoquée par des antigènes viraux présentés par une fraction des cellules tumorales.

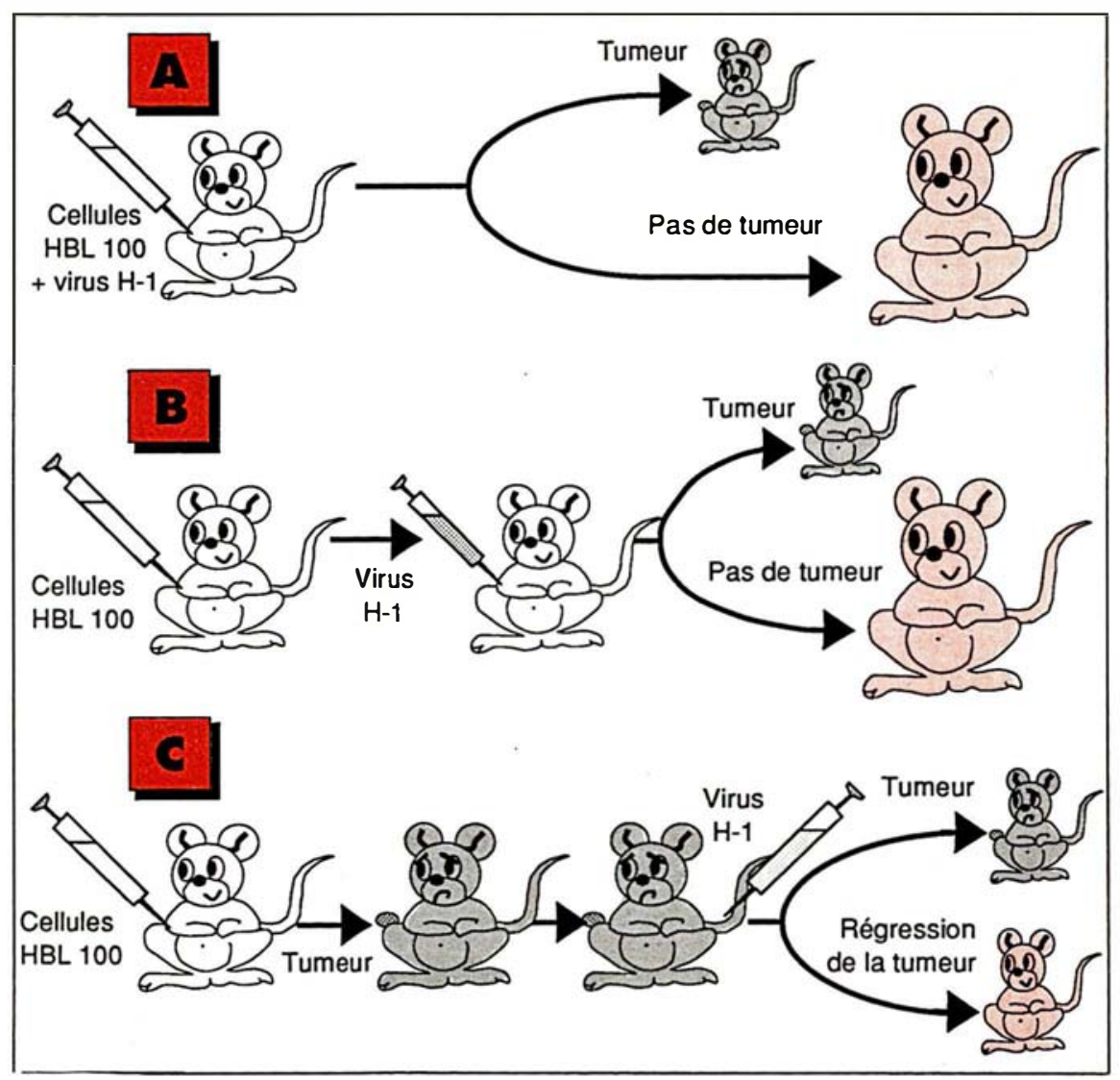

Figure 2. Schéma d'expériences démontrant l'aptitude du parvovirus $H-1$ à protéger des souris " nude " contre l'implantation de tumeurs d'origine humaine. Des animaux, soumis à l'inoculation de cellules épithéliales mammaires humaines transformées (HBL 100), ont été infectés par du virus $H$-1 simultanément (A) ou ultérieurement, avant (B) ou après (C) le développement de tumeurs. Les tailles respectives des souris porteuses et dépourvues de tumeurs indiquent les proportions d'animaux non protégés et protégés par l'infection parvovirale. Il apparaît que le virus $H-1$ prévient la formation de tumeurs avec une efficacité proche de $85 \%(A, B)$ et provoque la régression d'une fraction appréciable des tumeurs établies $(C)$. (D'après [17].) 


\begin{tabular}{|c|c|c|c|}
\hline \multicolumn{4}{|c|}{$\begin{array}{l}\text { FACTEURS PARVOVIRAUX SUSCEPTIBLES D'INTERFÉRER } \\
\text { AVEC LA VIE CELLULAIRE }\end{array}$} \\
\hline Perturbation cellulaire & $\begin{array}{l}\text { Effecteurs } \\
\text { parvoviraux }\end{array}$ & $\begin{array}{l}\text { Origine } \\
\text { des } \\
\text { cellules }\end{array}$ & Références \\
\hline $\begin{array}{l}\text { Effets directs } \\
\text { Inhibition de l'induction de } \\
\text { l'amplification de l'ADN }\end{array}$ & $\begin{array}{l}\text { Séquences termi- } \\
\text { nales de l'ADN } \\
\text { (AAV-2, -3, -5) } \\
\text { Protéines non } \\
\text { structurales Rep } \\
\text { (AAV-2) }\end{array}$ & $\begin{array}{l}\text { Hamster } \\
\text { Hamster }\end{array}$ & 20 \\
\hline $\begin{array}{l}\text { Inhibition de l'expression pro- } \\
\text { grammée par des promoteurs } \\
\text { hétérologues }\end{array}$ & $\begin{array}{l}\text { Protéines non } \\
\text { structurales Rep } \\
\text { (AAV-2)/NS } \\
\text { (H-1, MVMp) }\end{array}$ & $\begin{array}{l}\text { Homme, } \\
\text { souris }\end{array}$ & $21-23$ \\
\hline $\begin{array}{l}\text { Inhibition de la transformation } \\
\text { stable par de l'ADN exogène }\end{array}$ & $\begin{array}{l}\text { Protéines non } \\
\text { structurales Rep } \\
\text { (AAV-2)/NS } \\
\text { (H-1, B19, } \\
\text { MVMp) }\end{array}$ & $\begin{array}{l}\text { Homme, } \\
\text { rongeurs }\end{array}$ & $21,23-25$ \\
\hline $\begin{array}{l}\text { Inhibition de la transformation } \\
\text { oncogène in vitro }\end{array}$ & $\begin{array}{l}\text { Protéines non } \\
\text { structurales Rep } \\
\text { (AAV-2) }\end{array}$ & Souris & 26 \\
\hline Effet cytostatique & $\begin{array}{l}\text { Composants } \\
\text { du virion (AAV-2) }\end{array}$ & $\begin{array}{l}\text { Homme, } \\
\text { hamster }\end{array}$ & 27 \\
\hline Effet cytocide & $\begin{array}{l}\text { Protéines non } \\
\text { structurales NS } \\
\text { (MVMp) }\end{array}$ & $\begin{array}{l}\text { Homme, } \\
\text { souris }\end{array}$ & b \\
\hline $\begin{array}{l}\text { Effets indirects présumés } \\
\text { Inhibition de la capacité des cel- } \\
\text { lules néoplasiques à métas- } \\
\text { taser }\end{array}$ & Antigènes (AAV-1) & Hamster & 15 \\
\hline $\begin{array}{l}\text { Acquisition par les cellules tumo- } \\
\text { rales d'un pouvoir " vaccina- } \\
\text { teur " contre des réimplanta- } \\
\text { tions ultérieures }\end{array}$ & Antigènes (MVMp) & Souris & 19 \\
\hline
\end{tabular}

\section{RÉFÉRENCES}

14. Cukor G, Blacklow NR, Kibrick S, Swan IC. Effect of adeno-associated virus on cancer expression by herpesvirustransformed hamster cells. $J$ Natl Cancer Inst $1975 ; 55: 957-9$.

15. Blacklow NR, Cukor G, Kibrick S, Quinnan G. Interaction of adeno-associated viruses with cells transformed by herpes simplex virus. In : Ward DC, Tattersall $\mathrm{P}$, eds. Replication of Mammalian Parvoviruses. Cold Spring Harbor, New York : Cold Spring Harbor Laboratory, 1978 : 87-98.

16. Katz E, Carter BJ. Effect of adenoassociated virus on transformation of $\mathrm{NIH}$ $3 \mathrm{~T} 3$ cells by ras gene and on tumorigenicity of an NIH 3T3 transformed cell line. Cancer Res 1986 ; 46 : 3023-6.

17. Dupressoir T, Vanacker JM, Cornelis J, Duponchel N, Rommelaere J. Inhibition by parvovirus $\mathrm{H}-1$ of the formation of tumors in nude mice and colonies in vitro by transformed human mammary epithelial cells. Cancer Res 1989 ; 49 : 3203-8.

18. Yang DVM. Parvovirus-induced regression of canine transmissible venereal sarcoma. Am J Vet Res 1987 ; 48 : 799-800.

19. Guetta E, Graziani Y, Tal J. Suppression of Ehrlich ascites tumors in mice by minute virus of mice. $J$ Natl Cancer Inst $1986 ; 76: 1177-80$.

20. Bantel-Schaal U, zur Hausen $H$. Adeno-associated viruses inhibit SV40 DNA amplification and replication of herpes simplex virus in SV40-transformed cells. Virology $1988 ; 164: 64-74$.

21. Labow MA, Graf LH, Berns KI. Adeno-associated virus gene expression inhibits cellular transformation by heterologous genes. Molec Cell Biol 1987 ; 7 : 1320-5.

22. Rhode SL, Richard SM. Characterization of the trans-activation-responsive element of the parvovirus $\mathrm{H}-1$ P38 promoter. $J$ Virol 1987; 61 : 2807-15.

23. Brandenburger A, Legendre D, Avalosse B, Rommelaere J. NS-1 and NS-2 proteins may act synergistically in the cytopathogenicity of parvovirus MVMp. Viro$\log y 1990 ; 174: 576-84$.

24. Rhode SL. Construction of a genetic switch for inducible trans-activation of gene expression in eucaryotic cells. $J$ Virol 1987 ;

a Heilbronn, Bürkle, Stephan et zur Hausen (1989), Proc. EMBO Workshop "Molecular Biology of Parvoviruses ", p. 44.

b Brandenburger, Caillet-Fauquet, Legendre, Perros et Rommelaere (1989), ibid., p. 49 ; Naeger, Clemens, Tullis et Pintel (1989), ibid., p. 21.

\section{Effet inhibiteur des parvovirus sur la transformation cellulaire in vitro}

Les altérations cellulaires directes provoquées par les parvovirus et énumérées ci-dessus n'ont pas été démontrées jusqu'à présent dans des cellules tumorales in vivo. Leur contribution à l'oncosuppression reste donc spéculative. Toutefois, l'hypothèse selon laquelle des cellules transformées peuvent servir de cibles immédiates aux parvovirus est appuyée par une série de résultats obtenus au moyen de cultures cellulaires. Ces expériences indiquent que les parvovirus inhibent l'induction et/ou le maintien d'un phénotype transformé dans des conditions in vitro où seules des interactions directes entre les virus et les cellules transformées ou leurs précurseurs peuvent avoir lieu. Comme dans le cas de l'oncosuppression, l'inhibition parvovirale de la transformation in vitro concerne une variété de cellules humaines ou murines et d'oncogènes viraux ou cellulaires (Tableau III). Parmi les effecteurs viraux de la perturbation cellulaire mentionnés pré- 
Tableau III

EFFET INHIBITEUR DES PARVOVIRUS SUR LA TRANSFORMATION CELLULAIRE IN VITROc

\begin{tabular}{|c|c|c|c|c|}
\hline \multicolumn{3}{|c|}{ Transformation } & \multirow[b]{2}{*}{ Agent parvoviral antitransformant $c$} & \multirow[b]{2}{*}{ Référence } \\
\hline Cible & Agent inducteur ${ }^{b}$ & Altération de croissance & & \\
\hline $\begin{array}{l}\text { Cellules } \\
\text { de ron- } \\
\text { geurs }\end{array}$ & $\begin{array}{l}\text { Adénovirus } \\
\text { (Ad 5, Ad 12, SiAd), } \\
\text { papovavirus } \\
\text { (BPV-1, SV40), } \\
\text { oncogène cellulaire } \\
\text { (c-Ha-ras } 1 \text { ) }\end{array}$ & $\begin{array}{l}\text { Formation de foyers, } \\
\text { indépendance vis-à-vis } \\
\text { de l'ancrage, saturation } \\
\text { à haute densité }\end{array}$ & AAV-1, AAV-2, MVM & $\begin{array}{c}13,16,26, \\
28-30\end{array}$ \\
\hline $\begin{array}{l}\text { Cellules } \\
\text { humaines }\end{array}$ & $\begin{array}{l}\text { Papovavirus, (SV40), } \\
\text { origine carcino- } \\
\text { mateuse }\end{array}$ & $\begin{array}{l}\text { Indépendance vis-à-vis } \\
\text { de l'ancrage }\end{array}$ & $\mathrm{H}-1$ & 17,31 \\
\hline
\end{tabular}

a Inhibition de la transformation $\geqslant 50 \%$.

b Ad : Adénovirus : SiAd : Simian Adenovirus; BPV: Bovine Papilloma Virus ; SV : Simian Virus.

c Inoculation de parvovirus (particules ou DNA) avant, après ou au moment de la transformation.

cédemment, la famille des protéines Rep est impliquée dans la capacité du virus AAV-2 à empêcher la transformation in vitro [26] (Tableau II).

Ces observations posent la question de la sélectivité de l'attaque parvovirale vis-à-vis des cellules transformées. Il est probable que, dans certains cas, la réduction de la fréquence de transformation résulte, au moins en partie, d'effets non spécifiques. Ainsi, les particules parentales de virus AAV se sont avérées douées d'un pouvoir cytostatique qui affecte tout autant, voire davantage, des cellules normales que des cellules transformées [27]. Cette perturbation se manifeste après l'inoculation de quantités importantes de virus et ne requiert apparemment pas la réplication de ces derniers. Par ailleurs, les parvovirus peuvent également agir de manière sélective sur les cellules (pré)transformées. Par exemple, le virus MVMp inhibe très efficacement la transformation de cellules de souris qui, dans leur état normal, ne sont pas ou sont peu sensibles aux inoculums utilisés [28]. Cette composante spécifique de l'action antitransformante des parvovirus est particulièrement intéressante; elle épargne en effet les cellules saines et laisse entrevoir l'utilisation possible de ces virus pour la mise en évidence de changements cellulaires associés à la transformation néoplasique. Deux types d'altérations ciblées de cellules transformées ont été identifiés en présence de parvovirus et seront discutés dans les paragraphes qui suivent.

\section{Répression du phénotype transformé par les parvovirus}

Une première interaction spécifique des cellules transformées et des parvovirus, décrite initialement pour les virus $\mathrm{AAV}$, conduit à la suppression de caractères de transformation. L'infection par AAV n'aboutit à la production d'une descendance virale qu'avec l'aide de virus auxiliaires ou lorsque le déroulement du cycle cellulaire est altéré par des traitements particuliers [2]. Toutefois, diverses cellules transformées se sont révélées aptes à exprimer des gènes d'AAV en l'absence d'un taux appréciable de réplication de l'ADN viral. Cette expression parvovirale n'est apparemment pas cytotoxique mais est associée à l'extinction de différents traits du phénotype transformé ( $T a$ bleau IV A, p. 541). Ainsi l'inoculation de virus AAV à des cellules de hamster transformées par un adénovirus se traduit par une diminution spectaculaire de la concentration intracellulaire de l'antigène tumoral $58 \mathrm{~K}$ codé par la région $\mathrm{E} 1 \mathrm{~B}$ du virus transformant. Le mécanisme moléculaire de cette réduction n'est pas éclairci mais pourrait impliquer l'une ou l'autre protéine parvovirale Rep, étant donné le rôle de ces produits dans la suppression de la transformation in vitro et dans la régulation de l'expression génique (Tableau II).

Il convient également de signaler que les virus AAV pourraient exercer une inhibition semblable sur l'expression (en particulier la transcription) d'oncogènes cellulaires. Cette possibilité s'appuie sur des résultats présentés récemment pour $c$-myc et $c$-ras, respectivement par Schlehofer et Faisst et par Hermonat [Proc. EMBO Workshop "Molecular Biology of Parvoviruses "1989, p. 43 et 46]. En conclusion, la répression de gènes cellulaires ou viraux responsables du maintien du phénotype transformé, mérite d'être considérée comme l'un des modes possibles de l'action antitransformante des parvovirus.

\section{Exacerbation de stress cellulaires par les virus AAV}

Une relation entre la transformation cellulaire et l'ampleur de l'effet cytopathique des parvovirus a été mise en évidence dans deux situations distinctes. La première concerne l'interaction de virus AAV et de cellules soumises à différents stress de croissance induits notamment par des agents génotoxiques initiateurs de la tumorigenèse.

Les virus AAV ont longtemps été 


\section{RÉFÉRENCES}

25. Ozawa K, Ayub J, Kajigaya S, Shimada $T$, Young $N$. The gene encoding the nonstructural protein of B19 (human) parvovirus may be lethal in transfected cells. J Virol 1988 ; 62 : 2884-9.

26. Hermonat PL. The adeno-associated virus rep 78 gene inhibits cellular transformation induced by bovine papillomavirus. Virology 1989 ; 172 : 253-61.

27. Winocour E, Callaham MF, Huberman E. Perturbation of the cell cycle by adenoassociated virus. Virology $1988 ; 167$ : 393-9.

28. Casto BC, Goodheart CR. Inhibition of adenovirus transformation in vitro by AAV-1. Proc Soc Expl Biol Med 1972; 140 : 72-8.

29. Mousset S, Rommelaere J. Minute virus of mice inhibits cell transformation by simian virus 40 . Nature $1982 ; 300$ : 537-9.

30. Mousset S, Cornelis J, Spruyt N, Rommelaere J. Transformation of established murine fibroblasts with an activated cellular Harvey-ras oncogene or the polyoma virus middle $T$ gene increases cell permissiveness to parvovirus minute virus of mice. Biochimie 1986 ; 68 : 951-5.

31. Su ZZ, Luo ZY, Guo LP, Dupont F, Avalosse B, Rommelaere J. Positive selection of human cells lacking several transformation parameters from an SV40-transformed culture by means of parvovirus H-1. Carcinogenesis $1988 ; 9$ : 1395-400.

32. Schlehofer JR, Heilbronn R, GeorgFries $B$, zur Hausen $H$. Inhibition of initiator-induced SV40 gene amplification in SV40-transformed chinese hamster cells by infection with a defective parvovirus. Int $J$ Cancer 1983 ; 32 : 591-5.

33. Schlehof er JR, Ehrbar M, zur Hausen $\mathrm{H}$. Vaccinia virus, herpes simplex virus, and carcinogens induce DNA amplification in a human cell line and support replication of a helpervirus-dependent parvovirus. Virology $1986 ; 152$ : 110-7.

34. Schmitt J, Schlehof er JR, Mergener K, Gissman L, zur Hausen H. Amplification of bovine papillomavirus DNA by $\mathrm{N}$ methyl-N'-Nitro-Nitrosoguanidine, ultraviolet irradiation, or infection with herpes simplex virus. Virology $1989 ; 172$ : 73-81.

35. Heilbronn R, Schlehofer JR, zur Hausen $\mathrm{H}$. Selective killing of carcinogen-treated SV40-transformed chinese hamster cells by a defective parvovirus. Virology 1984; 136 : considérés comme des agents défectifs incapables de se répliquer sans l'aide d'un virus auxiliaire [2]. Il est toutefois apparu depuis peu que les perturbations sus-mentionnées confèrent transitoirement aux cellules qui les subissent l'aptitude à soutenir le déroulement au moins partiel du cycle des virus AAV en l'absence de virus auxiliaire. Cette réplication autonome des virus AAV interfère apparemment avec le métabolisme des cellules initiées, sans doute par l'intermédiaire des structures terminales de l'ADN parvoviral et/ou des protéines Rep (Tableau II). Il s'ensuit qu'en présence de virus AAV, les cellules initiées manifestent un taux réduit d'amplification de séquences d'ADN chromosomique [Yalkinoglu, Schlehofer et zur Hausen, ibid., p. 12] et peuvent même mourir (Tableau IV B). En d'autres termes, les virus AAV renforcent de façon synergique la toxicité intrinsèque des agents initiateurs et sont ainsi susceptibles de diminuer le risque d'apparition et de subsistance de cellules engagées dans la voie de la transformation.

En outre, comme l'expression d'un phénotype transformé semble prédisposer les cellules à l'induction d'un état de permissivité aux virus AAV [Yakobson et Winocour, ibid., p. 5], l'infection par ces agents pourrait également compromettre préférentiellement la survie de cellules néoplasiques préétablies exposées à l'un ou l'autre stress physiologique. Il est intéressant de signaler à ce propos que les traitements exerçant une action cytocide en synergie avec les virus AAV incluent le choc thermique et le facteur nécrosant de tumeurs (TNF) [Walz et Schlehofer, ibid., p. 37].

\section{Lyse préférentielle de cellules transformées par les virus $\mathrm{H}$-1 et MVMp}

L'interdépendance de la transformation cellulaire et du pouvoir cytocide des parvovirus apparaît dans une deuxième situation impliquant en particulier les virus $\mathrm{H}-1$ et MVMp. L'analyse de l'interaction de ces parvovirus avec des cultures cellulaires a révélé que de nombreuses lignées transformées de fibroblastes et de cellules épithéliales ou lymphoïdes d'origine humaine ou murine étaient nettement plus sensibles à l'infection virale que les cellules normales dont elles dérivent (Tableau $V A$ ). Cette aggravation de l'effet cytopathique des parvovirus est associée à la transformation in vitro par divers oncogènes viraux ou cellulaires et par des carcinogènes physicochimiques. Il s'ensuit que le virus $\mathrm{H}-1$ a pu être utilisé comme agent de sélection pour l'isolement de rares variants " normalisés " présents au sein d'une culture de cellules humaines rénales transformées [31]. Il semble que la transformation soit bien responsable de la sensibilisation cellulaire à l'infection parvovirale, étant donné la variation concomitante de ces deux paramètres dans des cellules transformées de façon conditionnelle par une oncoprotéine thermosensible [41]. Il convient d'ajouter que le renforcement, par la transformation, de l'action cytopathique des virus $\mathrm{H}-1$ et MVMp dépend de la nature de l'oncogène et de la cellule concernées (Tableau V B). Bien qu'il soit acquis fréquemment par suite de la transformation, l'état d'hypersensibilité à l'infection parvovirale n'est donc pas nécessaire à l'expression du phénotype transformé.

En outre, une série de lignées de cellules humaines établies à partir de tumeurs variées (fibrosarcomes, carcinomes épidermoïdes et mammaires, lymphomes) se sont avérées plus susceptibles d'être tuées par le parvovirus $\mathrm{H}-1$ que les cellules normales correspondantes (Tableau VA). Certains parvovirus sont donc capables d'induire un processus d'oncolyse dans des cultures de cellules. On ne connaît pas actuellement la contribution de l'établissement de la culture, et de son éventuelle dérive in vitro, à la vulnérabilité des cellules tumorales face aux parvovirus. Toutefois, les observations mentionnées ci-dessus justifient la prise en considération de l'oncolyse comme l'une des composantes potentielles de l'oncosuppression parvovirale.

Le mécanisme par lequel la transformation exacerbe l'action lytique des parvovirus n'est pas entièrement élucidé. Ce phénomène ne résulte pas, dans les cas étudiés, d'une stimu- 


\begin{tabular}{|c|c|c|c|c|}
\hline \multicolumn{5}{|c|}{$\begin{array}{l}\text { Tableau IV } \\
\text { ELLULES (PRÉ)NÉOPLASIQUES A L'INFECTION } \\
\text { IS ADÉNO-ASSOCIÉS (AAV) }\end{array}$} \\
\hline Origine des cellules & $\begin{array}{l}\text { Traitement } \\
\text { des cellules }\end{array}$ & Produits parvoviraux & Perturbation cellulaire & Référence \\
\hline $\begin{array}{l}\text { A. Hamster } \\
\text { (fibroblastes } \\
\text { transformés par } \\
\text { l'adénovirus 5) } \\
\text { Souris }\end{array}$ & Papillomavirus & $\begin{array}{l}\text { Transcrits } \\
\text { (AAV-2) } \\
\text { Protéines Rep } \\
\text { (AAV-2) }\end{array}$ & $\begin{array}{l}\text { Réversion de la transformation, } \\
\text { inhibition de la production de } \\
\text { l'antigène tumoral } 58 \mathrm{~K} \\
\text { Inhibition de la transformation } \\
\text { in vitro }\end{array}$ & $\begin{array}{l}13 \\
26\end{array}$ \\
\hline B. Homme, rongeurs & $\begin{array}{l}\text { Initiateurs } \\
\text { (carcinogènes } \\
\text { chimiques, } \\
\text { radiations, } \\
\text { herpès-et } \\
\text { poxvirus) }\end{array}$ & $\begin{array}{l}\text { Formes réplicatives } \\
\text { d'ADN, protéines } \\
\text { (AAV-2, }-3,-5)\end{array}$ & $\begin{array}{l}\text { Inhibition de l'amplification de } \\
\text { l'ADN } \\
\text { Effet cytocide }\end{array}$ & $20,32-34$ \\
\hline
\end{tabular}

\begin{tabular}{|c|c|c|c|c|c|c|}
\hline \multicolumn{7}{|c|}{$\begin{array}{l}\text { RÉPONSES SPÉCIFIQUES DES CELLULES TRANSFORMÉES A L'INFECTION } \\
\text { PAR LES PARVOVIRUS } \mathrm{H}-1 \text { ET/OU MVM } \mathrm{MP}_{\mathrm{p}}\end{array}$} \\
\hline \multirow[b]{2}{*}{ Cellules } & \multirow[b]{2}{*}{ Agent transformant } & \multicolumn{4}{|c|}{ Renforcement des effets parvoviraux dans les cellules transformées ${ }^{a}$} & \multirow[b]{2}{*}{ Référence } \\
\hline & & $\begin{array}{l}\text { Réplication } \\
\text { de I'ADN } \\
\text { parvoviral }\end{array}$ & $\begin{array}{l}\text { Expression } \\
\text { des gènes } \\
\text { parvoviraux }\end{array}$ & $\begin{array}{l}\text { Production } \\
\text { de parvovirus } \\
\text { infectieux }\end{array}$ & $\begin{array}{c}\text { Lyse } \\
\text { des cellules }\end{array}$ & \\
\hline $\begin{array}{l}\text { A. Majorité } \\
\text { des lignées } \\
\text { de cellules } \\
\text { fibroblastiques, } \\
\text { épithéliales et } \\
\text { lymphoïdes } \\
\text { d'origine } \\
\text { humaine ou } \\
\text { murine }\end{array}$ & $\begin{array}{l}\text { Divers oncogènes } \\
\text { viraux ou cellulai- } \\
\text { res, carcinogène } \\
\text { chimique, radia- } \\
\text { tion, origine } \\
\text { tumorale (fibro- } \\
\text { sarcome, carcino- } \\
\text { mes, leucémies) }\end{array}$ & Oui ou non & $\begin{array}{c}\text { Oui } \\
\text { (taux accru } \\
\text { de } \\
\text { transcription) }\end{array}$ & Oui ou non & $\begin{array}{c}\text { Oui } \\
\text { (effet } \\
\text { oncoly- } \\
\text { tique } \\
\text { in vitrol }\end{array}$ & $\begin{array}{c}17,19,29 \\
30,36-48\end{array}$ \\
\hline \multirow{2}{*}{$\begin{array}{l}\text { B. Fibroblastes } \\
\text { de rat } \\
\text { FR3T3 }^{\text {b }}\end{array}$} & $\begin{array}{l}\text { Papillomavirus } \\
\text { BPV-1 }\end{array}$ & Non & Non & Non & Non & 39 \\
\hline & $\begin{array}{l}\text { Oncogène } \\
\text { Ha-ras-1 } \\
+ \text { ou - BPV-1 }\end{array}$ & Non & Oui & Oui & Oui & 39 \\
\hline $\begin{array}{l}\text { Cellules } \\
\text { de rat NRKb }\end{array}$ & Ha-ras-1 & Non & Non & Non & Non & 38 \\
\hline
\end{tabular}

a L'augmentation de l'effet parvoviral dans les cellules transformées par rapport aux cellules parentales est indiqué par Oui, l'absence de renforcement par Non.

b Les cellules parentales NRK et FR3T3 se distinguent par le blocage du cycle parvoviral, respectivement avant et après la réplication de I'ADN. 


\section{RÉFÉRENCES}

36. Guetta E, Mincberg M, Mousset S, Bertinchamps C, Rommelaere J, Tal J. The selective killing of transformed rat cells by minute virus of mice correlates with elevated viral gene expression but does not require infectious virus production. $J$ Virol 1990 ; 64 : 458-62.

37. Cornelis JJ, Becquart P, Duponchel N, et al. Transformation of human fibroblasts by ionizing radiation, a chemical carcinogen, or simian virus 40 correlates with an increase in susceptibility to the autonomous parvoviruses $\mathrm{H}-1$ virus and minute virus of mice. J Virol 1988; 62 : 1679-86.

38. Van Hille B, Duponchel N, Salomé N, et al. Limitations to the expression of parvoviral nonstructural proteins may determine the extent of sensitization of EJ-rastransformed rat cells to minute virus of mice. Virology 1989 ; 171 : 89-97.

39. Salomé N, Van Hille B, Duponchel N, et al. Sensitization of transformed rat cells to parvovirus MVMp is restricted to specific oncogenes. Oncogene $1990 ; 5: 123-30$.

40. Walton TH, Moen PT, Fox E, Bodnar JW. Interactions of minute virus of mice and adenovirus with host nucleoli. $J$ Virol $1989 ; 63$ : 3651-60.

41. Salomé N, Van Hille B, Geuskens M, Rommelaere J. Partial reversion of conditional transformation correlates with a decrease in the sensitivity of rat cells to killing by the parvovirus minute virus of mice but not in their capacity for virus production : effect of a temperature-sensitive v-src oncogene. J Virol 1989; 63 : 4797-807.

42. Chen $Y Q$, de Foresta F, Hertoghs J, Avalosse B, Cornelis J, Rommelaere J. Selective killing of simian virus 40-transformed human fibroblasts by parvoviruses H-1. Cancer Res 1986; 46 : 3574-9.

43. Cornelis JJ, Spruyt N, Spegelaere $P$, et al. Sensitization of transformed rat fibroblasts to killing by parvovirus minute virus of mice correlates with an increase in viral gene expression. J Virol $1988 ; 62$ : 3438-44.

44. Faisst S, Schlehofer JR, zur Hausen $H$. Transformation of human cells by oncogenic viruses supports permissiveness for parvovirus H-1 propagation. J Virol $1989 ; 63$ : 2152-8.

45. Rhode SL, Paradiso PR. Parvovirus replication in normal and transformed human cells correlates with the nuclear translocation of the early protein NS1.J Virol $1989 ; 63$ : 349-55.
Boukamp P, Fusenig NE, Rommelaere J. Sensitization of human keratinocytes to killing by parvovirus $\mathrm{H}-1$ takes place during their malignant transformation but does not require them to be tumorigenic. Carcinogenesis $1989 ; 10: 163-7$

47. Toolan H, Ledinko N. Growth and cytopathogenicity of $\mathrm{H}$-viruses in human and simian cell cultures. Nature $1965 ; 208$. 812-3.

48. Bass LR, Hetrick FM. Human lymphoblastoïd cells as hosts for parvovirus $\mathrm{H}-1$ and rat virus. $J$ Virol $1978 ; 25$ : 486-90.

49. Avalosse BA, Berrijal S, Chen YQ Cassiman JJ, Rommelaere J. Identification of a transformation-sensitive nuclear protein from normal human fibroblasts, that specifically interacts with minute virus of mice DNA and correlates with cell resistance to the parvovirus. Molec Carcinogenesis 1989 ; 2 . 245-51.

50. Siegl G. Biology and pathogenicity of autonomous parvoviruses. In : Berns KI, ed. The Parvoviruses. New York: Plenum Press, 1984 : 297-362.

51. Sprecher-Goldberger S, Thiry L, Lefèbvre N, Dekegel D, de Halleux F. Complement fixation antibodies to adenovirusassociated viruses, adenoviruses, cytomegaloviruses and herpes simplex viruses in patients with tumors and in control individuals. Am J Epidemiol 1971 ; 94 : 351-8.

52. Mayor HD, Drake S, Stahmann J, Mumford DM. Antibodies to adenoassociated satellite virus and herpes simplex in sera from cancer patients and normal adults. Am J Obstet Gynecol 1976; 126 : 100-4.

53. Georg-Fries B, Biederlack S, Wolf J, zur Hausen $\mathrm{H}$. Analysis of proteins, helper dependence and seroepidemiology of a new human parvovirus. Virology 1984; 134 : 64-71.

54. Kurtzman G, Cohen B, Meyers P, Amunullah A, Young NS. Persistent B19 parvovirus infection as a cause of severe chronic anaemia in children with acute lymphocytic leukaemia. The Lancet $1988 ; 2$. 1159-62.

55. Malarme M, Vandervelde D, Brasseur M. Parvovirus infection, leukaemia, and immunodeficiency. The Lancet 1989 ; 1 : 1457.

56. Toolan HW, Saunders EL, Southam $\mathrm{CM}$, Moore AE, Levin AG. $\mathrm{H}-1$ virus viremia in the human. Proc Soc Exp Biol Med $1965 ; 119$ : 711-5. lation de la pénétration des virions inoculés et ne requiert pas la production de nouvelles particules. En revanche, les cellules transformées sensibles se distinguent des cellules résistantes par leur plus grande aptitude à répliquer et/ou exprimer (en particulier transcrire) le génome parvoviral (Tableau V). Cette permissivité accrue a pour effet d'enrichir les cellules infectées en protéines virales non structurales dont la toxicité (Tableau II) contribue vraisemblablement au processus d'oncolyse. Il n'est toutefois pas exclu que la transformation cellulaire puisse également modifier l'action des facteurs parvoviraux cytotoxiques [41].

Outre son intérêt pour l'élimination de cellules transformées, l'oncolyse induite par les parvovirus est fascinante du point de vue fondamental, car elle reflète le contrôle du cycle viral par des facteurs cellulaires modulés en fonction de la transformation maligne. Ces facteurs pourraient stimuler la multiplication parvovirale et être activés dans les cellules transformées, ou au contraire réprimer l'expression virale mais être inactivés lors de la transformation. Des candidats pour ces deux types de facteurs cellulaires ont été identifiés récemment parmi les protéines nucléaires qui interagissent directement ou indirectement avec le génome du virus MVMp [40, 49]. Ces recherches en sont à leurs balbutiements mais promettent de valoriser les parvovirus comme moyens d'investigation de marqueurs cellulaires de la transformation maligne.

\section{Parvovirus et cancer chez I'homme}

L'homme peut être infecté par divers parvovirus spécifiquement humains (AAV/2/3/5, B19) ou plus communément rencontrés chez des rongeurs (H-1) $[1-5,50]$. Les individus contaminés subissent une séroconversion dont le maintien suggère l'établissement d'un état porteur persistant du virus. En principe, une surveillance anticancéreuse pourrait s'exercer dans ces conditions, par suite de la réactivation et de l'expression du pouvoir antinéoplasique des parvovirus lors de l'apparition de clones de cellules transformées. Certaines don- 
nées épidémiologiques sont compatibles avec cette possibilité. Une corrélation inverse a en effet été établie entre le risque de cancer, en particulier de carcinome cervical, et l'indice de séropositivité traduisant une infection antérieure par des virus AAV [51-53]. Ces études n'excluent toutefois pas que d'autres paramètres, de nature socioéconomique, soient responsables des différences observées.

En tout état de cause, il est indubitable que des tumeurs peuvent apparaître et se développer chez l'homme en dépit de la présence de parvovirus. Ainsi, des infections chroniques par le virus B19 ont été décrites chez des patients souffrant de leucémies $[54,55]$. Une cause possible de cet échappement à la surveillance parvovirale consiste en l'incompatibilité de la tumeur et du tropisme tissulaire du virus. Par ailleurs, quand bien même la tumeur offrirait un terrain favorable à la réplication virale, l'ampleur de la réponse antinéoplasique peut être limitée par la quantité de virus initialement présent, la production locale de nouvelles particules ou encore la riposte immunitaire de l'hôte [5]. Ces restrictions rendent compte du fait que divers parvovirus ont été isolés de tumeurs humaines primaires ou transplantées, ou encore de lignées de cellules tumorales humaines [50, 53]. Ces limitations pourraient également expliquer l'insuccès d'une tentative ancienne de traitement par le virus $\mathrm{H}-1$, de deux patientes atteintes d'un ostéosarcome avancé, disséminé et résistant aux thérapies conventionnelles [56]. L'infection a été suivie d'une virémie et d'une séroconversion mais est demeurée asymptomatique. Bien qu'une stabilisation temporaire du taux sérique de phosphatase alcaline ait été obtenue dans l'un de ces cas, le développement tumoral n'a pu être enrayé par les doses de virus $\mathrm{H}-1$ utilisées.

Il ressort de la discussion qui précède que l'oncosuppression parvovirale reflète probablement la régulation de la réplication virale en fonction de la prolifération et de la différenciation cellulaires. Il s'ensuit que l'utilisation éventuelle des parvovirus pour une thérapeutique anticancéreuse chez l'homme nécessite au préalable une

$\mathrm{m} / \mathrm{s} n^{\circ} 6$ vol. 6 , juin 90 meilleure définition des facteurs cellulaires impliqués dans la multiplication parvovirale, ainsi que l'élucidation du mode d'action cytotoxique de ces virus. On ne peut s'attendre à ce que la modulation des interactions parvovirus-cellules engendre une réponse antinéoplasique universelle ou de type tout ou rien. Il serait particulièrement intéressant à cet égard d'évaluer la spécificité de l'effet antitumoral des parvovirus au moyen de modèles animaux de cancérogenèse ciblée, par exemple des lignées de souris transgéniques exprimant des oncogènes déterminés. De telles recherches devraient mettre à l'épreuve la possibilité d'exploiter l'oncotropisme des parvovirus et l'apparente innocuité de certains de ces agents chez l'homme, pour produire des facteurs cytotoxiques parvoviraux ou hétérologues dans des tumeurs humaines

\section{Remerciements}

Les travaux du laboratoire ont bénéficié du soutien de la Commission des Communautés européennes, du Cnrs, de l'Inserm, de la Fondation de France, de l'ARC et de la Ligue contre le cancer (France), et également du Frsm, des Services de programmation de la politique scientifique, du Commissariat général aux relations internationales, de l'OEuvre belge du cancer, de la Caisse générale d'épargne et de retraite, de la Banque nationale et de Solvay et $\mathrm{C}^{\text {ic }}$ (Belgique). Nous remercions aussi nos collègues $M$. Bossens et $\mathrm{D}$. Stehelin pour leur relecture de ce manuscrit, et également T. Dupressoir et D. Rommelaere pour les illustrations.

\section{TIRÉS A PART}

J. Rommelaere.

\section{Summary}

Oncosuppression by parvoviruses

Fundamental as well as clinical interest in parvoviruses rests on the subordination of their lytic cycle to cellular factors that are expressed as a function of proliferation and differentiation. Therefore, little wonder that oncogenic transformation of various mammalian, including human, cells, is often accompanied by a change in their sensitivity to parvoviral attack. This modulation finds testimony in oncotropic and oncolytic responses that were demonstrated in vivo and in vitro, respectively. In laboratory animals, certain parvoviruses proved able to inhibit tumor development. Interestingly, tumorigenic human cells can be the target for such an oncosuppressive activity upon implantation in recipient animals. Altogether, these properties give hope of using parvoviruses as probes to unravel the process of malignant transformation. It remains to be determined whether the parvoviral anticancer surveillance achieved in animals can be exploited to therapeutic ends in humans. 